\title{
PECULIARIDADES DEL TURISMO RURAL DE BALEARES
}

\author{
Jose Ramón Cardona \\ Universitat de les Illes Balears España \\ jramon.cardona@terra.es \\ Antoni Serra Cantallops \\ Universitat de les Illes Balears España \\ antoni.serra@uib.es
}

\section{RESUMEN}

El turismo rural tiene por objetivo revitalizar las zonas rurales. En general, el turismo rural en España ha dado lugar a establecimientos con tipologías, grados de confort y precios muy variables. Las islas Baleares no han quedado fuera de este nuevo sector y han desarrollado un turismo rural con características diferentes a otras regiones.

En Baleares es un sector que complementa al turismo tradicional con una oferta de pequeños establecimientos situados en las zonas rurales de las islas. En muchos casos se trata de una oferta equivalente a cuatro o cinco estrellas, y dirigida o gestionada por personas con experiencia turística previa. La demanda destaca por estar formada por personas extranjeras que permanecen en las islas una semana de media.

El objetivo de este trabajo es describir, la legislación, la evolución cuantitativa y los elementos más característicos de la oferta y demanda del turismo rural, con sus diferencias insulares.

PALABRAS CLAVE: Turismo rural, Baleares, oferta, demanda, legislación. 


\title{
PECULIARITIES OF RURAL TOURISM IN THE BALEARES ISLANDS
}

\author{
Jose Ramón Cardona \\ Universitat de les Illes Balears España \\ jramon.cardona@terra.es \\ Antoni Serra Cantallops \\ Universitat de les Illes Balears España \\ antoni.serra@uib.es
}

\begin{abstract}
Rural tourism aims to revitalize rural areas. In general, rural tourism in Spain has led to the establishment of a supply that varies regarding types, levels of comfort and prices. The Baleares Islands are not an exception and rural tourism has emerged with characteristics that differ from other regions.

In the Baleares Islands, rural tourism is a sector that complements traditional tourism with a small tourism supply located in rural areas of the islands. In many cases this supply is equivalent to four or five stars and is managed by people with previous travel experience. Demand is mainly composed of foreigners who stay in the islands for about a week.

In this context, this paper aims to describe the legislation underlying rural tourism development on the island, examine the growth of the tourism supply and investigate the main characteristic of the current supply and demand for rural tourism with their insular differences. KEYWORDS: rural tourism, Baleares, supply, demand, legislation.
\end{abstract}

KEYWORDS: rural tourism, Baleares, supply, demand, legislation. 


\section{INTRODUCCIÓN}

El turismo rural es una forma de turismo que ha aparecido en las últimas décadas debido al surgimiento de un nuevo tipo de turista que busca el contacto con la naturaleza y la tranquilidad (Bote, 1988; Colombram, 2009; Yagüe, 2002). Esta nueva fórmula de turismo tiene la característica de situarse en el espacio rural, con establecimientos más dispersos y pequeños.

El turismo rural tiene como uno de sus fines básicos ayudar al desarrollo de las zonas rurales evitando su deterioro social (Saxena \& Ilbery, 2008). Desde la Unión Europea y las Administraciones estatales y locales se pretende que la agricultura ecológica y los productos amparados por denominaciones de calidad sustituyan la agricultura tradicional. Esta nueva agricultura tiene producciones muy inferiores y se pretende que el turismo rural complemente las rentas del sector primario equiparando las rentas rurales a las rentas urbanas (Ribas, 1993). Este objetivo es a muy largo plazo, ya que a día de hoy tanto la agricultura ecológica y las denominaciones de calidad como el turismo rural aún representan volúmenes insuficientes.

El turismo rural no tiene normas que permitan una tipología homogénea a escala nacional o europea. Consecuentemente, es difícil definir el turismo rural, aunque una buena aproximación sería definirlo como actividad turística en el espacio rural destinada a un turismo interesado en el conocimiento y disfrute de entornos rurales y naturales (Bardón, 1987; Bote, 1992; Crosby, 1993; Fuentes, 1995; Valdés, 1996).

Una definición más acotada implicaría expulsar de ella a ofertas consideradas de turismo rural. Cada comunidad autónoma ha regulado por su cuenta, existiendo múltiples legislaciones con múltiples tipologías de establecimientos. Esta variedad de tipos de establecimientos provoca que la demanda sufra cierto desconcierto sobre la oferta existente. Esta variabilidad entre las comunidades autónomas se ve incrementada por el hecho de que dentro de un mismo tipo de establecimiento de una determinada comunidad autónoma se pueden englobar establecimientos con unos servicios y comodidades muy diferentes.

El objetivo pretendido es describir el turismo rural que se ha desarrollado en las Islas Baleares (legislación, oferta y demanda), comparándolo con el turismo rural de otras regiones españolas. El interés se encuentra en las características del turismo rural de las Islas, las cuales lo convierten en peculiar dentro de la oferta nacional. 


\section{TURISMO RURAL EN ESPAÑA}

Es en 1967 cuando se producen los primeros antecedentes de lo que podríamos considerar turismo rural en nuestro país. Desde entonces esta actividad ha tenido un continuo crecimiento y ha motivado el interés y preocupación de las Administraciones, especialmente comunidades autónomas. Corrales (1993a) define y distingue al turismo rural de otros modelos turísticos por sus características cualitativas, que hacen del turismo rural una oferta para consumir el tiempo de ocio y vacaciones de forma distinta. Estas características cualitativas son:

- Es generalizada la fijación de un límite de capacidad en la normativa. Ello permite disfrutar de una estancia tranquila, sin aglomeraciones y en contacto directo con la naturaleza y sus moradores. La oferta de turismo rural tiene una marcada dispersión geográfica dando un enorme grado de diferenciación entre los establecimientos.

- Utiliza pequeñas infraestructuras, preferiblemente ligadas a las explotaciones rurales o a espacios naturales de valor ecológico. En el turismo rural se suele hacer uso de edificaciones rurales de arquitectura tradicional y de las infraestructuras ya existentes en la zona, sin llegar a cambiar significativamente el entorno.

- Es una alternativa turística que sostiene los recursos naturales y sociales de la zona de actuación.

- Consiste en una oferta que revitaliza social y económicamente y que desarrolla los contactos entre las poblaciones rurales y foráneas, enriqueciéndose ambas. Pero en el futuro se deberá evitar caer en la monoactividad del turismo rural (Albaladejo \& Díaz, $2003,2005)$ que provocaría un aumento de los precios y una indeseable estacionalidad en la dedicación laboral.

- Debe ser una oferta de gestión local e integrada. El turismo rural debe implicar a la sociedad residente en la organización, gestión y animación de la oferta turística, y debe existir una coordinación entre los agentes que facilite el acceso de la demanda a la oferta de forma rápida y simple.

Nos encontramos frente a una fórmula turística novedosa que se basa en el uso racional y sostenido de los recursos naturales y sociales del área en donde se ubica (Corrales, 1993a). El objetivo principal del turismo rural es recuperar el medio rural tanto económicamente como socialmente (Cavaco 1995; Hoggart, Buller, \& Black, 1995; Williams \& Shaw, 1998). Este objetivo principal se concreta en varios objetivos más precisos (Broom, 1992; Crosby, 1993; Gannon, 1994; García, 2003, p. 81; Roberts \& Halls, 
2001; Sharpley \& Sharpley, 1997): recuperar las viviendas y la arquitectura tradicional del mundo rural para uso turístico; el desarrollo de una industria complementaria de la actividad agrícola que permita, junto con políticas de creación de denominaciones de calidad, revitalizar el mundo rural permitiendo que se obtenga la rentabilidad suficiente para equiparar el nivel de vida al de las zonas urbanas; vinculado al objetivo anterior se busca frenar el despoblamiento del espacio rural, el cual ha sido muy acusado en las últimas décadas en muchas zonas de España, y se pretende desarrollar un turismo respetuoso con la naturaleza y que permita poner en contacto la cultura rural y urbana evitando el desconocimiento mutuo, especialmente de los habitantes de las ciudades hacia el mundo rural.

La evolución de la normativa del turismo rural empieza con el traspaso de las competencias en gestión turística a las comunidades autónomas. La Constitución Española de 1978 estableció una nueva organización administrativo-territorial descentralizada con unos nuevos entes llamados Comunidades Autónomas. A estos nuevos entes territoriales la Constitución les confiere capacidad de autogobierno, disponiendo de competencias administrativas y legislativas. En el artículo 148.1 se señalan las competencias que podrán asumir las comunidades, y entre ellas se menciona la ordenación del territorio, el patrimonio monumental y la promoción y ordenación del turismo, siempre en su ámbito territorial. Habitualmente las disposiciones reguladoras del Turismo Rural han sido Decretos y Órdenes administrativas dictados por los Entes Autonómicos en ejercicio de su competencia en promoción y ordenación del turismo. También hay que tener en cuenta la legislación europea, que se incorporó a partir del Tratado de Adhesión de España a las Comunidades Europeas de 1986, y que afecta al turismo rural porque suele situarse en zonas que son receptoras de ayudas al desarrollo de la U.E.

La primera legislación de turismo rural se remonta a principios de los años ochenta y ya es normativa dictada por las comunidades autónomas en ejercicio de sus competencias. Estas primeras normas, normalmente con forma de Decreto, vinieron a regular ex novo el sector creando las distintas modalidades de establecimientos. Estos Decretos suelen contener, en un articulado no muy extenso, definiciones de los términos y condiciones o trámites que deben seguirse para su puesta en práctica. La novedad del sector hace que sea una regulación breve e incompleta que con el tiempo se irá completando y perfeccionando. En casi todos los casos la regulación del objeto Turismo Rural ha venido acompañado de un conjunto de normas, generalmente Ordenes y algún Decreto de la Consejería o las Consejerías responsable del Turismo Rural, en las que se modifica, adapta o reforma la legislación anterior, según se iban detectando imprecisiones en las primeras normativas dictadas. También se crearon ayudas para el desarrollo de los objetivos marcados en los primeros decretos que regulaban el sector. 
Corrales (1993b) clasifica esta normativa en dos tipos. Un tipo formado por Decretos y Órdenes que regulan el Turismo Rural, estableciendo los objetivos que se pretenden con la potenciación de este sector (Blaine \& Golan, 1993; Dernoi, 1991; Valdés \& del Valle, 2003), las modalidades de alojamientos y los requisitos que han de cumplir. Como ejemplo de este tipo de normas tenemos el Decreto 30/1991, de 4 de abril, de la Comunidad Autónoma de las Islas Baleares. El otro tipo de normativa establece las ayudas económicas para la promoción de esta modalidad turística. Como ejemplo de la legislación que actúa en el ámbito del Turismo Rural a través de ayudas y subvenciones tenemos las Órdenes de 21 de agosto de 1991 y de 15 de enero de 1992 de la Comunidad Autónoma de las Islas Baleares. El hecho de que en muchos casos fuera una materia con imprecisiones ha hecho que en algunas comunidades autónomas regularan el Turismo Rural dentro de la normativa turística general, a la espera de que fuera posible realizar una regulación específica y precisa del sector (Corrales, 1993b).

Cuadro $N^{o}$ 1: Alojamientos de turismo rural en España (año 2011)

\begin{tabular}{|l|r|r|r|}
\hline Comunidad Autónoma & $\begin{array}{c}\text { Alojamientos } \\
\text { estimados }\end{array}$ & $\begin{array}{c}\text { Plazas } \\
\text { estimadas }\end{array}$ & $\begin{array}{c}\text { Personal } \\
\text { empleado }\end{array}$ \\
\hline Andalucía & 1.342 & 10.920 & 2.108 \\
\hline Aragón & 1.111 & 8.552 & 1.242 \\
\hline Principado de Asturias & 1.345 & 11.882 & 1.625 \\
\hline Illes Balears & 203 & 3.554 & 823 \\
\hline Canarias & 681 & 4.033 & 983 \\
\hline Cantabria & 395 & 6.836 & 615 \\
\hline Castilla y León & 3.188 & 28.807 & 4.746 \\
\hline Castilla-La Mancha & 1.381 & 11.225 & 2.175 \\
\hline Cataluña & 1.732 & 13.848 & 2.239 \\
\hline Comunitat Valenciana & 991 & 9.250 & 1.462 \\
\hline Extremadura & 473 & 5.561 & 718 \\
\hline Galicia & 535 & 6.591 & 894 \\
\hline Comunidad de Madrid & 223 & 3.880 & 508 \\
\hline Región de Murcia & 272 & 2.984 & 360 \\
\hline C. Foral de Navarra & 677 & 4.869 & 876 \\
\hline País Vasco & 382 & 3.983 & 493 \\
\hline La Rioja & 106 & 987 & 123 \\
\hline TOTAL & $\mathbf{1 5 . 0 3 5}$ & $\mathbf{1 3 7 . 7 6 1}$ & $\mathbf{2 1 . 9 8 9}$ \\
\hline
\end{tabular}

Fuente: Encuesta de Ocupación en Alojamientos Turísticos (INE, datos de 2011) 
En los Decretos se mencionan los requisitos que se marcan a los establecimientos de Turismo Rural como imprescindibles y fundamentales para la autorización e inscripción en el correspondiente Registro de Actividad. Estos requisitos suelen hacer referencia a la ubicación de la vivienda, las características arquitectónicas, número máximo de plazas del establecimiento, dedicación del prestatario, requisitos técnicos, régimen de alojamiento, control de precios, facturación y reserva, y los procedimientos de inicio de actividad.

La variada legislación autonómica ha dado lugar a un heterogéneo subsector turístico que representa un pequeño porcentaje del global nacional, pero es de gran importancia para la dinamización económica de las regiones rurales donde prospera. La oferta existente y reconocida como turismo rural por las diversas legislaciones totalizaba en 2011 más de 137.000 plazas repartidas en 15.035 establecimientos de todo el país que daban trabajo a casi 22.000 personas de forma directa (Cuadro 1). Dentro de las diversas comunidades autónomas, destaca Castilla y León con más de 28.000 plazas y 3.000 establecimientos que dan trabajo a casi 5.000 personas. Otras regiones importantes son Cataluña, Andalucía y Asturias.

En cuanto a la demanda del turismo rural español, en 2011 los establecimientos de turismo rural abiertos alojaron a 2,715.986 personas que realizaron 7,696.369 pernoctaciones. La inmensa mayoría de la demanda es de origen nacional, ya que el mercado español representa el $87,6 \%$ de los turistas y el $80,0 \%$ de las pernoctaciones. La estancia media de los turistas fue de 2,83 días, aunque existieron diferencias entre los españoles (2,59 días) y los extranjeros (4,56 días). 
Gráfico No 1: Pernoctaciones en turismo rural en España (año 2011)

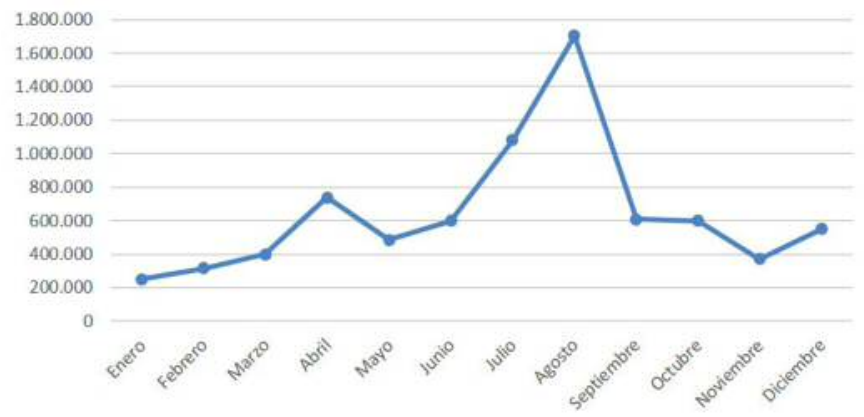

Fuente: Encuesta de Ocupación en Alojamientos Turísticos (INE, datos de 2011).

En cuanto a la distribución temporal, el turismo rural padece la misma pauta estacional del turismo tradicional (Gráfico 1), pero ligeramente suavizado por la existencia de puentes a lo largo del año y por la tendencia a repartir las vacaciones. A parte de la estacionalidad anual encontramos la estacional intrasemana. Por norma general los fines de semana muestran una ocupación 11 puntos superior a la media semanal, debido a que el turismo rural es una oferta muy típica de las escapadas de fin de semana.

Esta estacionalidad es más acusada en las regiones con mayor porcentaje de turismo nacional, como es el caso de Navarra o La Rioja (con más de 20 puntos de diferencia) y menor en las regiones con mayor demanda extranjera, como Canarias y Baleares (con menos de 5 puntos de diferencia).

Se puede afirmar que el turismo rural en España se caracteriza por una oferta heterogénea no muy importante cuantitativamente en el conjunto del sector turístico pero importante para el desarrollo de las regiones rurales, especialmente del centro y norte. La demanda se caracteriza por ser mayoritariamente españoles que realizan escapadas de fin de semana, predominantemente en verano y puentes. 


\section{EL TURISMO RURAL EN BALEARES}

Baleares es una de las comunidades autónomas con mayor volumen de turistas, lo que combinado con su pequeña extensión, la convierte en una región fuertemente dependiente del turismo. La oferta tradicional de Baleares la constituye el turismo de sol y playa, en sus diversas variantes, pero en las últimas décadas se ha intentado complementar, más que diversificar, la oferta tradicional con turismo alternativo (deportivo, naturaleza, náutico, rural, etc.). La finalidad pretendida es mantener el liderazgo de la región dentro del sector nacional e internacional.

El turismo rural en Baleares es de creación reciente, habiendo sólo algún establecimiento considerable como tal antes de la regulación del sector en 1991, y tiene un peso poco importante dentro de la oferta de las islas, representando el $1,26 \%$ de las plazas totales. Pero permite dinamizar las zonas rurales del centro y norte de las islas, las cuales poseen un menor desarrollo turístico.

\section{Normativa}

La regulación del turismo rural en las Islas Baleares empieza en 1991 con el Decreto 30/1991, de 4 de abril. Este Decreto realiza la primera definición de modalidades y criterios, y como se ha mencionado para el caso de España, se trata de una reglamentación ex novo con imprecisiones y lagunas que enseguida se hacen patentes, forzando a una posterior actividad reguladora para adaptar la normativa vigente a la realidad cambiante de un sector en expansión. Este hecho se observa por la continua elaboración de Decretos y Órdenes durante los primeros años. A día de hoy, la normativa básica que regula el Turismo Rural es la Ley 2/1999, de 24 de marzo, General Turística de las Islas Baleares, el Decreto 62/1995, de 2 de junio, y la Orden de 13 de octubre de 1995 de la Consellería de Turismo.

La Ley 2/1999, de 24 de marzo, General Turística de las Islas Baleares regula los elementos básicos de la oferta turística de las islas. Del turismo rural sólo menciona las definiciones de Hotel Rural (art. 25), de Turismo de Interior (art. 26) y de Agroturismo (art. 27), y el hecho de constituir una excepción a la condición de baja definitiva de una autorización de apertura de establecimiento de alojamiento turístico para el otorgamiento de una autorización previa de establecimiento de alojamiento turístico (art. 52.a). En la práctica sólo afecta a temas administrativos referentes a las tramitaciones, ya que las definiciones son muy imprecisas, dejando su concreción a las disposiciones con rango de decreto que lo regulan específicamente. 
El Decreto 62/1995 deroga los Decretos precedentes en la materia, entre ellos el Decreto 30/1991, de 4 de abril, por el cual se regulan las actividades de Agroturismo y Turismo Rural en las Islas Baleares, el Decreto 44/1992, de 8 de julio, por el cual se modifica el Decreto 30/1991, y el Decreto 2/1995, de 13 de enero, por el cual se regula la prestación de servicios turísticos en el medio rural de las Islas Baleares. La finalidad de este decreto es la regulación administrativa de los servicios que se prestan en el medio rural y que se estructuran en las modalidades de Hotel Rural, Agroturismo, Turismo de Interior y Otras Ofertas Complementarias (art. 1):

- Se define Hotel Rural como "la prestación de servicios turísticos, por motivo de vacaciones y mediante precio, que se realiza en una vivienda construida antes del día 1 de enero de 1940, situada en terrenos no urbanizables y que disponga de una superficie de terreno que quedará afecta a la actividad turística (mínimo $50.000 \mathrm{~m} 2$ )", es decir queda vinculada a la explotación turística (art. 2.1, 2.5 y 3.a.4).

- Se define Agroturismo como "la prestación de cualquier tipo de servicio turístico, por motivo de vacaciones y mediante precio, que se realiza en una vivienda construida antes del día 1 de enero de 1960, situada en terrenos no urbanizables y en una finca que sea explotación agrícola, ganadera o forestal (el conjunto de bienes y derechos están organizados empresarialmente para la producción agraria) y que ocupe como mínimo media U.T.H." (art. 2.2, 2.6 y 2.7). Siempre deben coexistir la actividad turística y la actividad agraria. La existencia de la explotación agraria debe justificarse mediante el certificado expedido por la Consellería de Agricultura y Pesca, el cual debe presentarse para obtener la autorización de apertura y en el tercer trimestre natural de cada año (art. 3.b.2).

- Se define Turismo de Interior como "la prestación de servicios turísticos, por motivo de vacaciones y mediante precio, que se realiza en viviendas situadas en el centro histórico de los núcleos urbanos que estén situadas a una distancia mínima de 500 metros de la zona turística más próxima, que tengan la construcción y la parcela donde se sitúa con la tipología tradicional del entorno urbano en que se encuentre, que constituyan una sola vivienda y que hayan estado construidas antes del día 1 de enero de 1940” (art. 2.3).

- "Se entiende por Otras Ofertas Turísticas Complementaras los servicios turísticos o de carácter general que se consideren atracciones turísticas. Esta Oferta Complementaria será compatible con cualquier otra modalidad regulada por este Decreto y se autorizará independientemente" (art. 2.4).

"La Consellería de Turismo podrá otorgar las dispensas de cumplimiento de algún o algunos de los requisitos que se exigen (Cuadro 2) y que de manera razonada se 
soliciten, siempre que esto no reduzca el confort ni las medidas sanitarias, de seguridad industrial y de protección contra incendios" (art. 9). A la Consellería de Turismo, a los Consells Insulares corresponde la autorización de la modalidad y la inscripción en el correspondiente registro, sin perjuicio del resto de autorizaciones que puedan existir (art. 10, modificado por Ley 2/1999, de 24 de marzo).

Cuadro $\mathrm{N}^{\circ}$ 2: Condiciones mínimas en los alojamientos de turismo rural

\begin{tabular}{|c|c|c|c|}
\hline & HR: Hotel Rural & AG: Agroturismo & TI: Turismo de Interior \\
\hline Edificación & $\begin{array}{l}\text { Construida antes del } \\
01 / 01 / 1940 . \\
\text { No se pueden realizar } \\
\text { obras para aumentar el } \\
\text { volumen construido o } \\
\text { que alteren la tipología } \\
\text { arquitectónica. } \\
\text { Diversos edificios o la } \\
\text { totalidad de uno en uso } \\
\text { turístico exclusivo. } \\
\text { Mucho confort } \\
\text { en construcción, } \\
\text { instalaciones, mobiliario } \\
\text { y decoración. } \\
\text { Debe cumplir la Ley } \\
\text { 3/1999, de } 4 \text { de mayo, de } \\
\text { mejora de accesibilidad } \\
\text { y supresión de barreras } \\
\text { arquitectónicas, y el } \\
\text { Decreto 20/2003, de } 28 \\
\text { de febrero. }\end{array}$ & $\begin{array}{l}\text { Construida antes } \\
\text { del 01/01/1960. } \\
\text { No se pueden } \\
\text { realizar obras } \\
\text { para aumentar } \\
\text { el volumen } \\
\text { construido o que } \\
\text { alteren la tipología } \\
\text { arquitectónica. } \\
\text { Debe cumplir la } \\
\text { Ley } 3 / 1999 \text {, de } 4 \\
\text { de mayo, de mejora } \\
\text { de accesibilidad } \\
\text { y supresión } \\
\text { de barreras } \\
\text { arquitectónicas, y el } \\
\text { Decreto } 20 / 2003, \text { de } \\
28 \text { de febrero. }\end{array}$ & $\begin{array}{l}\text { Construida antes del } \\
01 / 01 / 1940 . \\
\text { Tipología tradicional del } \\
\text { entorno urbano. } \\
\text { Que configure una sola } \\
\text { edificación en su totalidad y } \\
\text { sin que se admitan otros usos } \\
\text { distintos del turístico. } \\
\text { No se pueden realizar obras } \\
\text { para aumentar el volumen } \\
\text { construido o que alteren la } \\
\text { tipología arquitectónica. } \\
\text { Mucho confort en acabados, } \\
\text { instalaciones, mobiliario y } \\
\text { decoración. } \\
\text { Debe cumplir la Ley } 3 / 1999 \text {, } \\
\text { de } 4 \text { de mayo, de mejora de } \\
\text { accesibilidad y supresión de } \\
\text { barreras arquitectónicas, y el } \\
\text { Decreto } 20 / 2003 \text {, de } 28 \text { de } \\
\text { febrero. }\end{array}$ \\
\hline
\end{tabular}




\begin{tabular}{|c|c|c|c|}
\hline Ubicación & $\begin{array}{l}\text { Terreno no urbanizable } \\
\text { y en parcela mínima de } \\
50.000 \mathrm{~m}^{2} \text { afecta a la } \\
\text { actividad ( } 30.000 \mathrm{~m}^{2} \text { en } \\
\text { el caso de Formentera). } \\
\text { Superficie construida } \\
\text { no superior al } 2 \% \text { de } \\
\text { la parcela o a } 1.500 \mathrm{~m}^{2} \\
\text { en el caso de Ibiza y } \\
\text { Formentera. } \\
\text { Excepción: fincas } \\
\text { rústicas incorporadas } \\
\text { al núcleo urbano por } \\
\text { crecimiento de este. }\end{array}$ & $\begin{array}{l}\text { Terreno no } \\
\text { urbanizable y en } \\
\text { finca de explotación } \\
\text { agrícola, ganadera } \\
\text { o forestal con un } \\
\text { mínimo de } 1 / 2 \text { UTH } \\
\text { (Unidad-Trabajo- } \\
\text { Hombre), es decir } \\
960 \text { horas año de } \\
\text { trabajo. } \\
25.000 \mathrm{~m}^{2} \text { afectos a } \\
\text { la actividad ( } 20.000 \\
\mathrm{~m}^{2} \text { en el caso de } \\
\text { Formentera). }\end{array}$ & $\begin{array}{l}\text { Barrios antiguos de núcleos } \\
\text { urbanos situados a más } \\
\text { de } 500 \text { metros de la zona } \\
\text { turística más cercana } \\
\text { (POOT). }\end{array}$ \\
\hline Capacidad & $\begin{array}{l}\text { Máximo } 25 \text { unidades de } \\
\text { alojamiento y } 50 \text { plazas. }\end{array}$ & $\begin{array}{l}\text { Máximo } 12 \\
\text { unidades de } \\
\text { alojamiento y } 24 \\
\text { plazas. }\end{array}$ & $\begin{array}{l}\text { Máximo } 8 \text { unidades de } \\
\text { alojamiento y } 16 \text { plazas. }\end{array}$ \\
\hline $\begin{array}{l}\text { Régimen de } \\
\text { Explotación }\end{array}$ & $\begin{array}{l}\text { Obligatorio desayuno y } \\
\text { media pensión. } \\
\text { Optativo pensión } \\
\text { completa. }\end{array}$ & $\begin{array}{l}\text { Coexistencia de } \\
\text { actividad agrícola, } \\
\text { ganadera o forestal } \\
\text { con la turística. } \\
\text { Obligatorio } \\
\text { desayuno. } \\
\text { Optativo media } \\
\text { pensión o pensión } \\
\text { completa. }\end{array}$ & $\begin{array}{l}\text { Obligatorio desayuno. } \\
\text { Optativo media pensión o } \\
\text { pensión completa. }\end{array}$ \\
\hline Clasificación & Única. & Única. & Única. \\
\hline
\end{tabular}




\begin{tabular}{|c|c|c|c|}
\hline $\begin{array}{l}\text { Requisitos } \\
\text { Mínimos }\end{array}$ & $\begin{array}{l}\text { Electricidad. } \\
\text { Agua potable y } \\
\text { evacuación y tratamiento } \\
\text { de aguas residuales. } \\
\text { Acceso rodado. } \\
\text { Medidas de seguridad y } \\
\text { prevención de incendios } \\
\text { (Decreto } 13 / 1985 \text {, de } \\
21 \text { de febrero y Real } \\
\text { Decreto } 2177 / 1996, \text { de } 4 \\
\text { de octubre). } \\
\text { Establecimiento } \\
\text { totalmente climatizado. } \\
\text { Vajilla, cristalería, } \\
\text { cubiertos y lencería de } \\
\text { alta calidad. }\end{array}$ & $\begin{array}{l}\text { Electricidad. } \\
\text { Agua potable } \\
\text { y evacuación y } \\
\text { tratamiento de } \\
\text { aguas residuales. } \\
\text { Acceso rodado. } \\
\text { Medidas de } \\
\text { seguridad y } \\
\text { prevención de } \\
\text { incendios (Decreto } \\
\text { 13/1985, de } 21 \\
\text { de febrero y Real } \\
\text { Decreto 2177/1996, } \\
\text { de } 4 \text { de octubre). }\end{array}$ & $\begin{array}{l}\text { Electricidad. } \\
\text { Agua potable y evacuación } \\
\text { y tratamiento de aguas } \\
\text { residuales. } \\
\text { Acceso rodado. } \\
\text { Medidas de seguridad y } \\
\text { prevención de incendios } \\
\text { (Decreto 13/1985, de } 21 \\
\text { de febrero y Real Decreto } \\
2177 / 1996, \text { de } 4 \text { de octubre). } \\
\text { Climatización en zonas } \\
\text { comunes y calefacción en } \\
\text { habitaciones. } \\
\text { Vajilla, cristalería, cubiertos } \\
\text { y lencería de buena calidad. }\end{array}$ \\
\hline $\begin{array}{l}\text { Unidades de } \\
\text { alojamiento }\end{array}$ & $\begin{array}{l}\text { Habitaciones dobles: } \\
\text { poder inscribir un } \\
\text { cuadrado de } 3,6 \mathrm{~m} \text { de } \\
\text { lado. } \\
\text { Habitaciones } \\
\text { individuales: poder } \\
\text { inscribir un cuadrado de } \\
3 \text { m de lado. } \\
\text { Habitación con salón: } \\
\text { mínimo } 25 \mathrm{~m}^{2} \text {. } \\
\text { Teléfono en las } \\
\text { habitaciones. } \\
\text { Disponer de una } \\
\text { habitación para personas } \\
\text { de movilidad reducida. }\end{array}$ & $\begin{array}{l}\text { Medidas de las } \\
\text { habitaciones } \\
\text { según normativa } \\
\text { sobre condiciones } \\
\text { de habitabilidad } \\
\text { (Decreto } \\
\text { 145/1997, de } 21 \text { de } \\
\text { noviembre). }\end{array}$ & $\begin{array}{l}\text { Habitaciones dobles: poder } \\
\text { inscribir un cuadrado de } 3 \\
\text { m de lado y superficie no } \\
\text { inferior a los } 15 \mathrm{~m}^{2} \text {. } \\
\text { Habitaciones individuales: } \\
\text { mínimo } 8 \mathrm{~m}^{2} \text {. } \\
\text { Habitación con salón: } \\
\text { mínimo } 23 \mathrm{~m}^{2} . \\
\text { Las habitaciones dobles con } \\
\text { cama de matrimonio pueden } \\
\text { reducir la superficie de la } \\
\text { habitación en un } 15 \% \text {. } \\
\text { Disponer de una habitación } \\
\text { para personas de movilidad } \\
\text { reducida, en planta baja si no } \\
\text { dispones de ascensor. }\end{array}$ \\
\hline $\begin{array}{l}\text { Salón y } \\
\text { comedor }\end{array}$ & $\begin{array}{l}\text { Salón: } 3,5 \mathrm{~m}^{2} \text { por } \\
\text { habitación (puede incluir } \\
\text { el bar). } \\
\text { Comedor: } 3,5 \mathrm{~m}^{2} \text { por } \\
\text { habitación. }\end{array}$ & $\begin{array}{l}\text { Espacio destinado a } \\
\text { desayunos. }\end{array}$ & $\begin{array}{l}\text { Salón: } 3 \mathrm{~m}^{2} \text { por habitación } \\
\text { (puede incluir el bar). } \\
\text { Comedor: } 3 \mathrm{~m}^{2} \text { por } \\
\text { habitación. }\end{array}$ \\
\hline Baño & $\begin{array}{l}\text { Uno completo por } \\
\text { habitación. }\end{array}$ & $\begin{array}{l}\text { Uno completo } \\
\text { por cada dos } \\
\text { habitaciones. }\end{array}$ & $\begin{array}{l}\text { Uno completo por } \\
\text { habitación. }\end{array}$ \\
\hline
\end{tabular}




\begin{tabular}{|c|c|c|c|}
\hline Cocina & $\begin{array}{l}\text { Suficiente para } \\
\text { dar servicio al } \\
\text { establecimiento. }\end{array}$ & Sin determinar. & $\begin{array}{l}\text { Suficiente para dar servicio } \\
\text { al establecimiento. }\end{array}$ \\
\hline Otros & $\begin{array}{l}\text { Recepción con cabina } \\
\text { telefónica cerrada e } \\
\text { insonorizada. } \\
\text { Repartidores de planta, } \\
\text { locales para equipajes y } \\
\text { almacén para lencería. } \\
\text { Aparcamiento señalizado } \\
\text { con una plaza para cada } \\
\text { dos habitaciones. } \\
\text { Piscina con una } \\
\text { superficie mínima de } \\
50 \mathrm{~m}^{2} \text { (cuadrada o } \\
\text { rectangular). }\end{array}$ & $\begin{array}{l}\text { Lugar para } \\
\text { almacenar } \\
\text { equipajes, utensilios } \\
\text { de limpieza y } \\
\text { lencería. }\end{array}$ & $\begin{array}{l}\text { Recepción con cabina } \\
\text { telefónica cerrada e } \\
\text { insonorizada. } \\
\text { Sólo se puede explotar } \\
\text { conjuntamente un máximo } \\
\text { de } 3 \text { edificaciones en cada } \\
\text { núcleo urbano por una } \\
\text { misma persona física o } \\
\text { jurídica, y en ningún caso } \\
\text { pueden ser confrontados. }\end{array}$ \\
\hline
\end{tabular}

Fuente: Colombram (2007), datos vigentes a 2012

La Orden de día 13 de octubre de 1995, de la Consellería de Turismo, regula los requisitos mínimos y el procedimiento administrativo aplicable para obtener las autorizaciones necesarias para la prestación de servicios turísticos en el medio rural, y crea el Registro de Actividades Turísticas en el Medio Rural (art. 1).

Esta Orden complementa la legislación de la prestación de servicios turísticos en el medio rural del Decreto 62/1995, de 2 de junio, y deroga las órdenes de la Consellería de Turismo de 9 de julio de 1991 y 6 de noviembre de 1992. Con esta Orden se crea el Registro de Actividades Turísticas en el Medio Rural, en el que deberán inscribirse antes de iniciar la actividad todos los establecimientos de las Islas Baleares que quieran ejercer una actividad regulada por el Decreto 62/1995 (art. 3 y 4).

\section{OFERTA DE TURISMO RURAL EN BALEARES}

En los últimos 20 años la oferta turística de Baleares se ha mantenido cuantitativamente constante y sólo ha vivido cambios debidos a mejoras cualitativas. Esto es debido, en gran parte, a la normativa de carácter restrictivo aprobada por el Govern Balear a finales de los ochenta. Los únicos aumentos autorizados por la legislación son en forma de hoteles de elevada categoría y establecimientos de turismo rural. En estos 20 años, la oferta de turismo rural ha pasado de inexistente a estar formada por 319 establecimientos, con 5.325 plazas (Gráfico 2) y más de 1.500 trabajadores empleados en verano. A pesar del rápido crecimiento del sector, representa un porcentaje muy pequeño de la oferta total de las islas ( $1,26 \%$ de las plazas), mostrando que se trata más de un complemento que de una alternativa al turismo tradicional. 
Gráfico $N^{\circ}$ 2: Evolución de la oferta de Turismo Rural en Baleares ( ${ }^{\circ}$ de plazas)

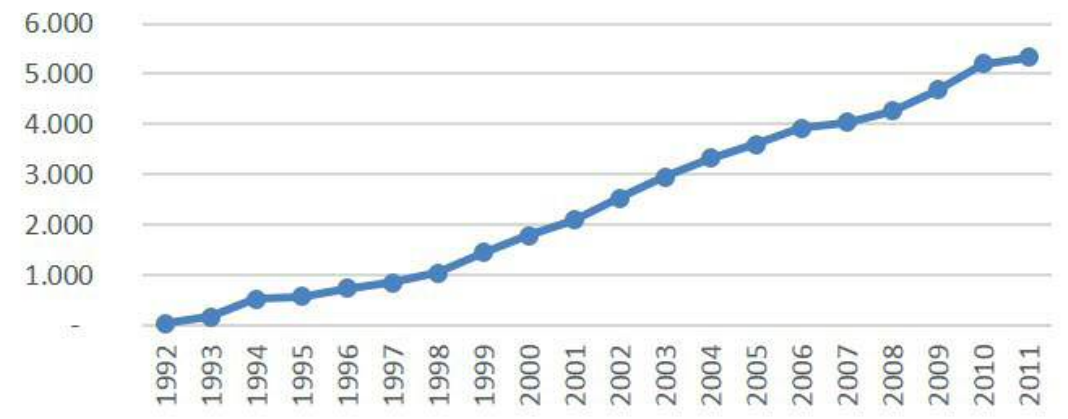

Fuente: Ibestat (datos descargados en 2012)

Por islas, vemos que Mallorca representa el 83,9\% de la oferta de turismo rural de las islas. El 10,0\% de la oferta se encuentra en Ibiza y el 6,0\% en Menorca. Formentera poseía un agroturismo de 12 plazas (abierto entre 2008 y 2010), pero en la actualidad no dispone de oferta de turismo rural. La oferta de turismo rural representa el 1,57\% de las plazas de Mallorca, el 0,65\% de las plazas de Menorca y el 0,67\% de las plazas de Ibiza.

La mayor presencia de establecimientos en Mallorca puede deberse a varios factores: Mallorca posee una mayor proporción de su superficie alejado de las zonas turísticas de costa y, por tanto, es mayor el territorio susceptible de desarrollo turístico rural; Mallorca es la isla con más abundancia de grandes propiedades susceptibles de convertirse en establecimientos de turismo rural; Menorca muestra una gran tradición de formulas de gestión rural como son la aparcería, lo cual dificulta el desarrollo turístico (Tur \& Garau, 2002); el sector primario de Menorca es el más potente y en mejores condiciones de Baleares, necesitando menos el turístico rural, y en Ibiza y Formentera la extensión de las propiedades es muy pequeña en general, dificultando el cumplimiento de los requisitos de apertura.

A la oferta turística se llega teniendo en cuenta distintas variables. Son necesarios unos recursos, relacionados con la naturaleza, la historia, la cultura, etc.; a esos recursos hay que añadirles una serie de servicios y equipamientos, que permitirán al visitante cubrir sus necesidades básicas y disfrutar de los atractivos del destino. La suma de recursos y servicios dará como resultado el producto turístico, capaz de satisfacer las 
motivaciones y expectativas de un segmento de mercado determinado. La unión de ese producto con un precio, unos canales de distribución y una promoción (comunicación), dará como resultado la oferta turística.

\section{- Producto.}

Baleares posee unos recursos naturales de importancia contrastada (dado el enorme volumen de turistas que atrae cada año) y unos recursos culturales y patrimoniales infrautilizados turísticamente hablando. Los servicios de alojamiento rural existentes son de tres tipologías distintas, según la reglamentación, y poseen buenos niveles de equipamiento. Los agroturismos son la fórmula más abundante de las tres con 205 establecimientos y 2.972 plazas (Cuadro 3). El 89\% del turismo de interior se concentra en Mallorca. Sólo ocho de los 72 establecimientos se sitúan fuera de Mallorca, y algunos como los de Ibiza son de apertura reciente (2010 y 2011). Cabe tener en cuenta que mientras las formulas de hotel rural y agroturismo se crearon en 1991, en el caso del turismo de interior se debe esperar a la normativa de 1995. Esto explica en parte la menor cantidad de oferta de turismo de interior.

Cuadro No 3: Oferta de Turismo Rural en Baleares (1 de enero de 2011)

\begin{tabular}{|l|r|r|r|r|r|r|r|r|}
\hline & \multicolumn{2}{|c|}{ Hotel Rural } & \multicolumn{2}{c|}{ Agroturismo } & \multicolumn{2}{c|}{$\begin{array}{c}\text { Turismo de } \\
\text { Interior }\end{array}$} & \multicolumn{2}{c|}{ Turismo Rural } \\
\cline { 2 - 9 } & Establ. & Plazas & Establ. & Plazas & Establ. & Plazas & Establ. & Plazas \\
\hline Mallorca & 31 & 1.137 & 173 & 2.494 & 64 & 839 & $\mathbf{2 6 8}$ & $\mathbf{4 . 4 7 0}$ \\
\hline Menorca & 4 & 121 & 11 & 128 & 5 & 72 & $\mathbf{2 0}$ & $\mathbf{3 2 1}$ \\
\hline Ibiza & 7 & 154 & 21 & 350 & 3 & 30 & $\mathbf{3 1}$ & $\mathbf{5 3 4}$ \\
\hline Formentera & & & & & & & & \\
\hline Baleares & $\mathbf{4 2}$ & $\mathbf{1 . 4 1 2}$ & $\mathbf{2 0 5}$ & $\mathbf{2 . 9 7 2}$ & $\mathbf{7 2}$ & $\mathbf{9 4 1}$ & $\mathbf{3 1 9}$ & $\mathbf{5 . 3 2 5}$ \\
\hline
\end{tabular}

Fuente: Ibestat (datos descargados en 2012) 
Los Hoteles rurales son el tipo de establecimiento menos numeroso pero de mayor tamaño. El tamaño medio de los hoteles rurales es de 33,6 plazas mostrando un cierto incremento de tamaño desde finales de los noventa (menos de 30 plazas). Los hoteles rurales más grandes son los de Mallorca (37 plazas) y los más pequeños los de Ibiza (22 plazas). Las otras dos formulas de establecimiento también muestran un cierto aumento en su capacidad media (los agroturismos pasaron de 10 plazas en 1997 a 14,5 en 2011 y los establecimientos de turismo de interior de 11 plazas en 1997 a 13,1 en 2011). Los agroturismos más pequeños son los de Menorca (11,6 plazas) y los más grandes los de Ibiza (16,7 plazas). En turismo de interior, los más grandes son los de Menorca (14,4 plazas) y los más pequeños los de Ibiza (10 plazas). La mayor parte de los alojamientos rurales de Baleares (55\%) poseen entre 6 y 10 habitaciones (de 12 a 20 plazas).

Una peculiaridad del turismo rural de Baleares es que no se encuentra regulada la Casa Rural, es decir la posibilidad de alquilar viviendas unifamiliares. Sólo se contemplan formatos que son variantes de lo que podríamos considerar minihoteles situados en zona rural. Este hecho es la causa de que el tamaño medio de los establecimientos sea el mayor de España (18 plazas de media). Sólo Madrid (17,5 plazas) y Cantabria (17,4 plazas) poseen establecimientos con un tamaño medio similar, mientras que la media nacional se encuentra en 9,1 plazas.

El tamaño y tipología de los establecimientos facilita un tipo de explotación predominantemente familiar, en especial en los agroturismo (Seguí, 2000). El 58\% de los empresarios poseía experiencia previa en el sector turístico y en el $60 \%$ de los casos estudios superiores (casi un $40 \%$ de ellos con estudios en turismo y hostelería). Dos tercios de los empresarios son hombres, mientras que en otras comunidades autónomas las mujeres son mayoría entre el empresariado de turismo rural (Colombram, 2009).

La nacionalidad del personal de los establecimientos de turismo rural guarda una cierta relación con la nacionalidad de sus clientes, pero la gran mayoría de los trabajadores de los establecimientos de turismo rural son de nacionalidad española. El conocimiento de idiomas del personal demuestra la adaptación a un mercado internacional: el conocimiento del inglés supera el $90 \%$, el alemán y francés más del $50 \%$, y otros idiomas (holandés, italiano) son hablados por una cuarta parte del personal (Seguí, 2000). 
Cuadro $\mathrm{N}^{\mathrm{o}}$ 4: Equipamiento de los establecimientos

\begin{tabular}{l|l|}
\hline Equipamiento & \% \\
\hline Calefacción en habitaciones & 97,26 \\
\hline Calefacción en zonas comunes & 94,52 \\
\hline Televisión en habitaciones & 91,78 \\
\hline Piscina & 89,04 \\
\hline Aire acondicionado en habitaciones & 86,30 \\
\hline Acceso a Internet & 76,71 \\
\hline Chimenea & 72,60 \\
\hline Aire acondicionado en zonas comunes & 64,38 \\
\hline Teléfono en habitaciones & 63,01 \\
\hline Restaurante & 56,16 \\
\hline Cocina en habitaciones & 23,29 \\
\hline Zona de Spa & 23,29 \\
\hline Cocina común para los clientes & 20,55 \\
\hline Gimnasio & 19,18 \\
\hline Instalaciones deportivas & 17,81 \\
\hline
\end{tabular}

Fuente: Colombram (2009), trabajo de campo realizado en 2006

El régimen de alojamiento predominante en los establecimientos de Baleares es el Alojamiento y Desayuno (86,3\%), seguido por la Media Pensión $(35,6 \%$ ) y la Pensión Completa (6,9\%). Estos establecimientos se caracterizan por poseer un nivel de equipamientos (Cuadro 4) superior a lo establecido por la norma, la cual ya es exigente. Además de los equipamientos de los establecimientos es necesario tener en cuenta los servicios complementarios que ofrecen estos establecimientos por si mismos o a través de contactos con otras empresas (Cuadro 5). Los establecimientos de Ibiza son los que muestran los mejores niveles de equipamientos y de oferta de ocio. Consecuentemente, Ibiza es la isla con los precios medios más elevados. 
Cuadro $\mathrm{N}^{\mathrm{0}}$ 5: Oferta de actividades complementarias

\begin{tabular}{|l|c|c|c|}
\hline Actividad & $\begin{array}{c}\text { En el propio } \\
\text { establecimiento }\end{array}$ & $\begin{array}{c}\text { En empresa } \\
\text { de ocio }\end{array}$ & Oferta total \\
\hline Alquiler de bicicletas & $34,25 \%$ & $57,35 \%$ & $91,60 \%$ \\
\hline Excursiones & $26,40 \%$ & $55,42 \%$ & $81,82 \%$ \\
\hline Excursión a caballo & $6,85 \%$ & $69,86 \%$ & $76,71 \%$ \\
\hline Práctica de deportes & $9,59 \%$ & $64,38 \%$ & $73,97 \%$ \\
\hline Actividades acuáticas & $1,37 \%$ & $71,23 \%$ & $72,60 \%$ \\
\hline Degustación de productos típicos & $39,43 \%$ & $19,10 \%$ & $58,53 \%$ \\
\hline Actividades relacionadas con la & $5,48 \%$ & $30,14 \%$ & $35,62 \%$ \\
artesanía & $0,00 \%$ & $26,35 \%$ & $26,35 \%$ \\
\hline Deportes de riesgo & $19,18 \%$ & $0,00 \%$ & $19,18 \%$ \\
\hline Labores agrícolas & $0,00 \%$ & $17,81 \%$ & $17,81 \%$ \\
\hline Pesca & $1,37 \%$ & $10,96 \%$ & $12,33 \%$ \\
\hline Rutas en todoterreno & $4,11 \%$ & $2,74 \%$ & $6,85 \%$ \\
\hline Caza & $10,96 \%$ & $5,48 \%$ & $16,44 \%$ \\
\hline Otras &
\end{tabular}

Fuente: Colombram (2009), trabajo de campo realizado en 2006

Los establecimientos rurales de Baleares suelen permanecer abiertos sólo una parte del año. De abril a octubre permanecen abiertos el 100\%, pero sólo el 30\% permanece abierto todo el año (Colombram, 2009).

\section{- Precio.}

En Baleares el precio de una estancia depende del establecimiento, de la temporada y de la habitación del establecimiento. Esta variación puede llegar a ser enorme y convierte la elección de un alojamiento en un rompecabezas de precios, temporadas y alojamientos. El cálculo de la relación precio calidad se convierte en algo muy complejo debido a la disparidad entre los servicios ofrecidos en establecimientos de la misma categoría y a la disparidad de precios. Una mayor homogeneidad entre los establecimientos ayudaría a que los consumidores pudieran comparar a la hora de elegir.

Las empresas de turismo rural de Baleares toman como referencia principal los precios de la competencia (59\%), junto a los costes (52\%). Los precios de las islas distan mucho de los establecidos en otras partes de España. El precio medio de la habitación doble se sitúa en más de $200 €$ en los Hoteles Rurales, $150 €$ en Agroturismos (en Ibiza 
llegan a $250 €)$ y $130 €$ en Turismo de Interior, en temporada alta. En temporada baja los precios son menores, pero aún así son superiores a los $150 €$ en Hoteles Rurales, $120 €$ en Agroturismos y $100 €$ en Turismo de Interior. Los establecimientos más económicos son los de Menorca al no tener unos niveles de confort y equipamientos tan elevados como en las otras islas.

\section{- Distribución.}

En Baleares, los canales de comercialización usados son muy diversos. El $100 \%$ de los establecimientos usa la contratación directa, casi el $90 \%$ Internet, el $72 \%$ agencias especializadas, el $50 \%$ los turoperadores tradicionales, y sólo el $48 \%$ los servicios de asociaciones de turismo rural. Pero no todos los canales generan el mismo porcentaje de clientes: Internet es la principal vía de comercialización con casi el 41\% de la contratación (sumando intermediarios de Internet y Web propia), los turoperadores tradicionales aportan el 23,8\% de los clientes y la contratación directa el 21,7\% (Garau, 2009). Ibiza es la isla con mayor grado de contratación directa (Colombram, 2009).

La principal vía de distribución de los establecimientos de turismo rural es la distribución directa vía teléfono o Internet. La práctica totalidad de establecimientos tienen página Web con información sobre el hotel y los servicios ofrecidos, una lista de precios y un formulario de reserva. Además todos reciben reservas por teléfono (o fax). Además, muchos establecimientos operan con mayoristas o agencias de viajes. El grado de distribución indirecta depende de la demanda directa que posean. Si tienen mucha demanda directa abandonan la distribución indirecta o la reducen, y si la demanda directa no es muy intensa mantienen la distribución indirecta a través de mayoristas o agencias de viajes.

\section{- Promoción.}

La principal dificultad para las empresas turísticas se encuentra en plasmar lo intangible, y los múltiples atributos del servicio. El instrumento comunicación adquiere especial relevancia al dar al producto una imagen que permite contrarrestar la intangibilidad del mismo. Internet es la principal herramienta de promoción del turismo rural de Baleares, en especial las páginas propias de los establecimientos: más del 98\% de los establecimientos disponen de página Web propia, el 56,9\% inserta anuncios en páginas de Internet, y el $45 \%$ utiliza estrategias de posicionamiento en buscadores. Los folletos, guías y anuncios en revistas pierden importancia con el paso de los años, aunque siguen siendo muy importantes (Garau, 2009). Internet es un método de promoción (permite dar a conocer el establecimiento a través de la Red), pero también es un método de distribución directa que permite poner en contacto el cliente y el establecimiento sin necesidad de intermediarios. 


\section{DEMANDA DE TURISMO RURAL EN BALEARES}

El turismo rural da servicio a un nuevo tipo de turista que no desea un paquete turístico estandarizado, rígido y masificado, les gusta sentirse diferentes y disfrutar de un turismo más individualizado, basado en la tranquilidad, el contacto con la naturaleza y la cultura. Son turistas más espontáneos e impredecibles, siendo la calidad fundamental para ellos (Colombram, 2009; García, 2003; Ioannides \& Debbage, 1998; Poon, 1993).

El turismo rural de Baleares recibió 123.693 turistas en 2011, según la Encuesta de Ocupación en Alojamientos Turísticos, y realizaron un total de 593.946 pernoctaciones. Si tenemos en cuenta que las Baleares reciben 10 millones de turistas extranjeros y otros dos millones de turistas nacionales al año, generando más de 100 millones de pernoctaciones, vemos que el turismo rural de las islas es una fracción muy pequeña del total del sector.

El 89,2\% de los turistas que se alojan en establecimientos rurales en España son españoles (15 de las 17 comunidades autónomas tienen más del $80 \%$ del turismo de origen nacional). Las dos únicas excepciones son las comunidades insulares (Baleares y Canarias), en las cuales los turistas extranjeros son mayoría. De estas dos, el caso más clamoroso es Baleares, ya que sólo el 22\% de los turistas es españoles y el $50 \%$ de estos son de las propias Islas. Cuando analizamos las pernoctaciones observamos que sólo el $13,7 \%$ de ellas se debe al turismo nacional. Del resto de comunidades, sólo Canarias, con el $29,8 \%$, posee un porcentaje inferior al $75 \%$ de pernoctaciones realizadas por turistas españoles. En cuanto a la estancia media, sólo en Canarias las estancias son más largas que en Baleares (5,9 días frente a 4,8 días) y ambos archipiélagos muestran estancias medias muy superiores a las del resto del país. Estas mayores estancias medias se deben a la gran presencia de turistas extranjeros, y a la lejanía de los mercados emisores. Cabe mencionar que en los primeros tiempos, las estancias eran mucho más largas que ahora en Baleares (Morro, 1993).

La distribución temporal de los turistas muestra un elevado nivel de estacionalidad (Gráfico 3), al igual que el resto del sector balear, pero la temporada es más extensa en el turismo rural, habiendo niveles de ocupación superiores a la media desde abril hasta octubre. Aunque los meses invernales muestran una ocupación muy inferior, se trata de niveles similares a la media anual de otras comunidades. El grado de ocupación de los establecimientos de Baleares es el más elevado del país, con un $40,1 \%$ de media anual, seguido de lejos por Navarra (23,7\%) y Euskadi (23\%). Además, la diferencia entre el grado de ocupación en fin de semana (44,4\%) y la media total es la más baja de España (sólo 4,3 puntos) después de la de Canarias (2 puntos). Es más que probable que la baja estacionalidad intrasemana se encuentre relacionada con la mayor 
duración de la estancia media.

Gráfico $\mathrm{N}^{\circ}$ 3: Pernoctaciones en turismo rural en Baleares (año 2011)

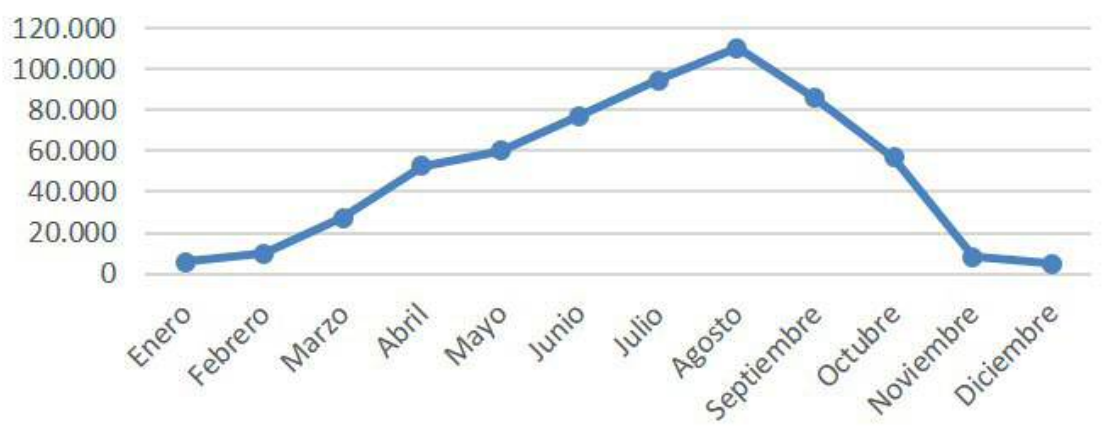

Fuente: Ibestat (datos descargados en 2012)

El principal mercado emisor es el alemán (40\%), seguido del español (22\%) y el británico (16\%). El predominio del mercado alemán ya se daba en los inicios del sector (Morro, 1993; Seguí, 2000). En Mallorca predomina el mercado alemán (más del 50\%), seguido del británico (16\%) y el español (15,5\%). En Menorca predomina el español (66\%), seguido del británico (16\%) y el alemán (8\%). En Ibiza predominan el mercado español (32\%) y el británico (24\%), seguidos del alemán (12\%). El 55,4\% de los turistas rurales tienen edades comprendidas entre los 30 y 45 años (Colombram, 2009; Garau, 2009), y en un principio eran incluso de mayor edad, 45 a 66 años (Morro, 1993). Tradicionalmente, los perfiles profesionales dominantes son de nivel medioalto (Colombram, 2009; Garau, 2009; Morro, 1993; Seguí, 2000): los altos ejecutivos, propietarios de empresas y profesionales liberales son el $40 \%$ de los turistas, y los cuadros intermedios el 22\%. Otra característica de los turistas rurales de Baleares es su elevada formación (el 60\% posee estudios universitarios) y sus elevadas rentas (el 50\% posee ingresos familiares anuales superiores a $60.000 €$ ).

Las fuentes de información más valoradas por los turistas son la experiencia previa, las opiniones de amigos e Internet (el $80 \%$ de los turistas consulta la pagina web del establecimiento antes de viajar). En los inicios, los folletos y los amigos eran las principales fuentes de información (Morro, 1993) pero, con la irrupción de Internet, los folletos han sido substituidos por la página web del establecimiento. Existe un elevado grado de repetición, y entre el $66 \%$ y el $75 \%$ de los turistas habían estado antes en las Islas (Colombram, 2009; Garau, 2009). Desde el principio, gran parte de los turistas rurales 
ya conocían las Islas (Morro, 1993), pero el grado de repetición no era tan elevada, rondando el 40\% (Seguí, 2000). En el caso de Ibiza también poseen gran relevancia las revistas especializadas y las guías. En Mallorca también son muy importantes los folletos y las agencias de viajes virtuales. La asistencia a ferias y los anuncios en prensa poseen poca relevancia salvo en el caso de Ibiza.

Cuadro $\mathrm{N}^{\circ}$ 6: Actividades realizadas durante la estancia

\begin{tabular}{|l|c|}
\hline Actividad & $\%$ \\
\hline Visitas a pueblos y mercados típicos & 74,31 \\
\hline Descubrir la gastronomía local & 69,69 \\
\hline Ir a la playa & 65,06 \\
\hline Tomar el sol en la piscina & 65,06 \\
\hline Pasear & 61,37 \\
\hline Visitas a lugares históricos y monumentos & 56,38 \\
\hline Ir de compras & 44,92 \\
\hline Visitas a parques o zonas naturales protegidas & 37,15 \\
\hline Senderismo & 36,04 \\
\hline Realizar actividades culturales & 19,04 \\
\hline Cicloturismo & 14,42 \\
\hline Actividades acuáticas & 14,23 \\
\hline Entretenimiento nocturno & 13,12 \\
\hline Golf & 12,75 \\
\hline Observación de pájaros & 12,38 \\
\hline Submarinismo & 10,35 \\
\hline Otras prácticas deportivas & 8,13 \\
\hline Pasear a caballo & 7,39 \\
\hline Visitas a parques acuáticos y de atracciones & 6,10 \\
\hline Pesca & 3,14 \\
\hline Caza & 0,74 \\
\hline Otras actividades & 5,55 \\
\hline
\end{tabular}

Fuente: Colombram (2009), trabajo de campo realizado en 2006 
Las principales alternativas al turismo rural de Baleares son Italia, Alemania y Austria, resultado lógico si tenemos en cuenta que el principal mercado emisor es el alemán. También poseen cierta significación destinos como Francia, Grecia y Reino Unido. Dentro de España, los principales destinos alternativos son Cataluña, Andalucía, Asturias y Canarias (Colombram, 2009; Garau, 2009).

Los turistas contratan en el $52,5 \%$ de los casos alojamiento y desayuno, en el $21,2 \%$ de los casos sólo alojamiento, y en el 15,4\% de los casos media pensión. El $60 \%$ viaja en pareja y el 30\% en familia. En los primeros años de desarrollo era muy habitual que viajaran en grupos de amigos en pareja y contrataban a través de turoperadores (Morro, 1993), en la actualidad la contratación directa es lo habitual y se viaja de forma más individualizada (Colombram, 2009; Garau, 2009). Las excursiones son una de las actividades (Cuadro 6) más destacadas desde los inicios del sector (Colombram, 2009; Garau, 2009; Morro, 1993). En Menorca predominan las actividades que impliquen un mayor contacto con la naturaleza, en Mallorca predominan las de tipo cultural y en Ibiza las compras y el ocio nocturno.

El nivel de satisfacción con la visita es bastante elevado (8,4 sobre 10), en especial entre los alemanes $(8,5)$ y el $70 \%$ tiene intención de repetir en los próximos tres años (Garau, 2009). El 56\% dice sentirse muy satisfecho y el 38\% bastante satisfecho con la experiencia. Lo que más valoran es la tranquilidad y descanso, el trato familiar, el entorno natural, el conocimiento de la gastronomía local, y el equipamiento del alojamiento (piscina, solárium, césped, jardines, etc.). Las principales críticas hacen referencia a los precios, la masificación de la destinación y a la degradación de las zonas turísticas. La confusión existente en cuanto a tipologías de establecimientos se observa en el hecho de que más de dos tercios de los turistas rurales de Baleares desconocen las diferencias entre los diferentes tipos de alojamientos existentes (Colombram, 2009).

El gasto total que realizan los turistas por persona y día es de $190 €$ (sumando $90 €$ de gasto en origen y $100 €$ de gasto en destino). Entre los diversos gastos, destacan bares, restaurantes y cafeterías ( $37 €$ de media) y compras $(24 €)$. La isla con mayor gasto medio de sus turistas rurales es Ibiza, que se sitúa un $40 \%$ por encima de la media de Baleares (Colombram, 2009; Garau, 2009; Tur \& Garau, 2002). Las estimaciones económicas son difíciles de realizar y los datos son muy variables, pero parece que el impacto económico del turismo rural sobre Baleares rondaría los 130 millones de euros, aunque algunos autores consideran que sería superior a los 200 millones (Colombram, 2009). 


\section{CONCLUSIONES}

El turismo rural es la prestación de servicios turísticos en el espacio rural y su finalidad es ayudar al desarrollo de las zonas rurales y sus pobladores para evitar un desfase entre el mundo rural y el mundo urbano. El turismo rural es una modalidad turística reciente que ha surgido junto con el ecologismo y la preocupación por el estrés y la salud. La regulación del turismo rural siempre ha sido autonómica y cada comunidad lo ha regulado según sus criterios y las particularidades de su territorio, conllevando una disparidad de normativas y tipologías de alojamiento.

En Baleares se inició la regulación del turismo rural en 1991, pero la evolución del sector hizo que en 1995 se regulara de nuevo. Las normas aprobadas en 1995 son las actualmente en vigor. En esta norma se regulan cuatro figuras: Hotel Rural, Agroturismo, Turismo de Interior y Otras Ofertas Complementarias. De todas ellas la más abundante es el Agroturismo, posiblemente por ser el alojamiento con menos requerimientos mínimos y que permite una mayor flexibilidad.

El sector resultante posee un conjunto de fortalezas y debilidades vinculadas a las peculiaridades de Baleares. Entre las fortalezas cabe mencionar: el entorno natural, el clima, y la tranquilidad; la existencia de buenas comunicaciones con los mercados emisores; el "Know How" turístico existente; la calidad y singularidad de los establecimientos de turismo rural; el alto grado de satisfacción (repetición y recomendación) de los turistas; las islas Baleares son muy conocidas facilitando la comercialización turística, y la oferta complementaria disponible es muy variada (Colombram, 2009; Garau, 2009).

Entre las debilidades cabe mencionar: el turismo rural, al igual que el tradicional, posee una gran estacionalidad veraniega; la excesiva presión sobre los recursos naturales; la disminución de la actividad agrícola y ganadera repercute en un menor cuidado del entorno natural y en una pérdida de atractivo; la accesibilidad del destino se reduce en la temporada invernal; la falta de especialización de los recursos humanos de los establecimientos; la promoción del turismo rural en el exterior es limitada; la excesiva concentración de la demanda en el mercado alemán, y la imagen de Baleares esta poco asociada al turismo rural (Colombram, 2009; Garau, 2009). Además, el turismo rural de Baleares posee unas características distintivas:

- Existe una elevada disparidad en la oferta de turismo rural española, causada en gran parte por la dispersión normativa originada por la transferencia de competencias en turismo a las diversas comunidades autónomas. Esto ha dado lugar a más de 50 tipos distintos de alojamientos de turismo rural. Baleares es un caso amplificado de esta 
disparidad nacional.

- En general se exige en la normativa que las edificaciones sean construcciones tradicionales de la zona. En Baleares, al igual que en Cataluña y Galicia, se exige acreditar una antigüedad mínima (Colombram, 2007), mientras que en otras comunidades autónomas se aceptan construcciones modernas que respeten la estética tradicional. Este hecho hace que el crecimiento del turismo rural balear este más limitado.

- La oferta balear se caracteriza por estar formada por establecimientos definibles como pequeños hoteles en zona rural. La legislación no incluye las Viviendas Turísticas de Vacaciones, conocidas en el resto de España como Casas Rurales, dentro de la clasificación de turismo rural. Estas Viviendas Turísticas Vacacionales representan unos 650 establecimientos (Colombram, 2009). Esto implica que sea la región con mayor tamaño medio de los establecimientos rurales (18 plazas).

- En Baleares no existe un sistema de clasificación de los establecimientos según su calidad, como si existe en otras comunidades. Aunque en general tienen niveles de confort elevados, algunos establecimientos son más austeros.

- El turismo rural se fomento en sus orígenes para complementar las rentas rurales pero en la actualidad es la principal fuente de ingresos de muchos establecimientos y la función de explotación agrícola un simple requisito formal, a diferencia de otros lugares. Se tiende hacia un desarrollo hotelero en el medio rural ya que un porcentaje significativo de los establecimientos es de empresarios hoteleros, siendo el turismo rural de Baleares una fuente de plazas hoteleras de elevada calidad evitando las restricciones de la Ley General de Turismo (Colombram, 2009).

- En Baleares, la oferta se ha dirigido desde sus inicios a cubrir una demanda internacional, en especial de origen alemán, con elevadas rentas familiares. Mientras que en la Península se encuentra orientado al mercado nacional, en Baleares la mayoría de los clientes son extranjeros (con la excepción de Menorca, donde dos tercios son españoles).

- Menorca posee el sector más parecido al resto de España, con equipamientos y servicios menos suntuosos, precios más moderados, mayor contacto con la naturaleza, importante asociacionismo empresarial y gran presencia de clientes españoles. Ibiza es el polo opuesto en cuanto a oferta: mayor lujo y confort de los agroturismos; precios más elevados; un mayor uso y diversidad de medios de promoción y comercialización, y una clientela que busca menos la tranquilidad que en el resto de islas y más disfrutar del ocio nocturno. Ibiza es la isla con el turismo rural más dispar de Baleares y posiblemente abunde lo que Albaladejo, Díaz y Molera (2004) denominan turista en alojamiento rural. - En muchos casos, la decoración y el mobiliario no es el propio de la zona, ni siquiera es antiguo y rústico, debido a que los empresarios no pertenecen a la comunidad local (muchos son ciudadanos extranjeros). Dos terceras partes de los propietarios o gestores poseen estudios universitarios y el $60 \%$ de ellos tenía experiencia previa en el sector turístico. La mayoría de los empresarios de turismo rural de Baleares son hombres, mientras que en otras regiones son mayoría las mujeres. 
- El asociacionismo de los establecimientos de las islas es variable, oscilando entre el 92\% de Menorca y el 44\% de Ibiza, y suele deberse a las facilidades de promoción que permite (Colombram, 2009). En general el asociacionismo es bajo y fragmentado en Baleares, diferencia importante con otras comunidades, en especial a la hora de la comercialización.

- En Baleares, la estrategia de precios en la penetración de mercado es de descremación frente a la mayoritaria estrategia de penetración en el resto de España (García, 2003). El precio medio de las habitaciones supera los $120 € /$ día siendo en muchos casos superior a los $200 € /$ día (Colombram, 2009). La oferta de Baleares posee precios muy elevados, y superiores a la mayoría de la oferta nacional.

- Los principales canales de distribución son Internet, los folletos promocionales y las guías turísticas. Las principales fuentes de información de los turistas son Internet, los amigos y la experiencia previa. Lo más habitual es la contratación directa vía Internet, teléfono o fax. Con el paso de los años los folletos y guías se han visto eclipsados por las páginas Web en la promoción y distribución, pero este hecho no es ni mucho menos exclusivo de Baleares. Lo que sí es distinto en las Islas es la poca importancia de las asociaciones en la promoción y distribución.

- La estacionalidad del turismo rural es inferior a la del turismo tradicional. Aunque también posee una fuerte concentración de la demanda durante los meses de verano, el periodo de gran afluencia turística es mayor en el caso del turismo rural que en el del turismo tradicional. En relación con la media nacional, la temporada veraniega de Baleares es más larga pero es más fuerte el descenso invernal y no se percibe un pico debido a la semana santa.

- El perfil del turista rural no ha sufrido modificaciones sustanciales con el paso de los años. Este perfil se corresponde con una persona de mediana edad, de clase mediaalta, con ingresos elevados, de nacionalidad alemana y de alto nivel educativo que pasa una semana de vacaciones en compañía de su pareja, que ha visitado con anterioridad las Islas y busca relajarse y disfrutar de un entorno agradable y tranquilo, escapando de la rutina diaria. El perfil del turista rural es parecido al del resto de España, salvo por diversos aspectos característicos de Baleares: la estancia media es muy superior, el mercado principal es extranjero, el nivel de ingresos familiares es superior y muestran menos interés por las actividades rurales. Destacan entre las actividades de los turistas rurales de Baleares la playa, las compras y el ocio nocturno por ser elementos poco habituales en el turismo rural.

- Los principales destinos alternativos al turismo rural de Baleares son Italia, Alemania, Austria, Francia, Grecia y Reino Unido. Dentro de España, los destinos alternativos son Cataluña, Andalucía, Asturias y Canarias. Al poseer un mercado emisor eminentemente extranjero los destinos competidores son también eminentemente extranjeros.

El resultado es un turismo rural de tipo hotelero, elevado confort y precios, enfocado a un mercado extranjero de clase media-alta, gestionado por personas con 
experiencia previa en el sector y relativamente alejado del concepto tradicional de turismo rural. A pesar de que el turismo rural ha despertado el interés de los académicos por su novedad y por ser distinto y alternativo al turismo tradicional de sol y playa, aún se necesita seguir trabajando para obtener datos de mayor fiabilidad y conocer mejor sus debilidades y fortalezas si se quiere que posea un desarrollo prospero y sostenible. En este aspecto Baleares no es la excepción.

\section{BIBLIOGRAFIA}

Albaladejo, I. P., \& Díaz, M. T. (2003). Un modelo de elección discreta en la determinación del perfil del turista rural: una aplicación a Murcia. Cuadernos de Turismo, 11, 509-525.

Albaladejo, I. P., \& Díaz, M. T. (2005). Rural tourism demand by type of accommodation. Tourism Management, 26(6), 951-959.

Albaladejo, I. P., Díaz, M. T., \& Molera, L (2004). Turista rural versus turista en alojamiento rural. Estudios Turísticos, 160, 85 -102.

Bardón, E. (1987). El Turismo rural en España: Algunas iniciativas públicas. Estudios Turísticos, 94, 63-76.

Blaine, T. W., \& Golan, M. (1993). Demand for rural tourism: An exploratory study. Annals of Tourism Research, 20(4), 770-773.

Bote, V. (1988). Turismo en Espacio Rural: Rehabilitación del Patrimonio y de la Economía local. Madrid: Ed. Popular.

Bote, V. (1992). Rehabilitación del Patrimonio Sociocultural y de la Economia Local. Madrid: Ed. Popular.

Broom, G. (1992). Pricing the countryside: The context. En Talbot, H. (ed.). Our Priceless Countryside: Should it be Priced? Bristol: CRRAG, pp. 21-33.

Cavaco, C. (1995). Rural tourism: The creation of new tourism spaces. En Montanari, A., \& Williams, A. (ed.). European tourism: Regions, Spaces and Restructuring, Chichester: Wiley, pp. 129-149.

Colombram, M. (2007). El Turisme en el Medi Rural a les Illes Balears. Anàlisi de la Normativa. Col•lecció Estudis Turístics, nº 7. Palma de Mallorca: Govern Balear.

Colombram, M. (2009). Análisi Estratégica del Turismo en el Medi Rural: el Cas de les Illes Balears. Tesis doctoral. Universitat de les Illes Balears.

Corrales, L. (1993a). Apuntes para la definición y concepto de turismo rural. En Andanzas I, Cuadernos de la Escuela Regional de turismo de Castilla y León. Edita Fundación cultural Sta. Teresa. Diputación de Ávila Servicio de Publicaciones.

Corrales, L. (1993b). Estudio de la normativa autonómica sobre turismo rural. En Andanzas II, Cuadernos de la Escuela Regional de turismo de Castilla y León. Edita Fundación cultural Sta. Teresa. Diputación de Ávila Servicio de 
Publicaciones.

Crosby, A. (dir.) (1993). El Desarrollo Turístico Sostenible en el Medio Rural. Madrid: Centro Europeo de Formación Ambiental y Turística (CEFAT).

Dernoi, I. (1991): About rural and farm tourism. Tourism Recreation Research, 16(1), 3-6.

Fuentes, R. (1995). Análisis de las principales características de la demanda de turismo rural en España. Estudios Turísticos, 127, 19-52.

Gannon, A. (1994). Rural tourism as a factor in rural community economic development for economies in transition. Journal of Sustainable Tourism, 2(1-2), 51-60.

Garau, J. B. (2009). El Turisme Rural a Balears 2008. Col•lecció Estudis Turístics, no 10. Palma de Mallorca: Govern Balear.

García, B. (2003). Marketing del Turismo Rural. Madrid: Editorial Esic-Pirámide

Hoggart, K., Buller, H., \& Black, R. (1995): Rural Europe, Identity and Change. London: Arnold.

Ibestat. Web Site: http://ibestat.caib.es [consultado el 10 de octubre de 2012]

INE. Web Site: http://www.ine.es [consultado el 10 de octubre de 2012]

Ioannides, D., \& Debbage, K. G. (ed.) (1998). The Economic Geography of the Tourist Industry. London: Routledge.

Morro, A. (1993). Perfil de l'usuari d'agroturisme a Mallorca. En La Formació, la reabilitació y les noves modalitats turístiques. III Jornades de Geografia del Turisme. Palma: UIB, pp. 225-234.

Poon, A. (1993). Tourism, Technology and Competitive Strategies. Wallingford: CABI International.

Ribas, M. (1993). Cap a un desenvolupament integrat: l'agricultura ecològica en unió amb l'agroturisme. En La Formació, la reabilitació y les noves modalitats turístiques. III Jornades de Geografia del Turisme. Palma: UIB, pp. 267-271.

Roberts, L. \& Hall, D. (2001). Rural Tourism and Recreation: Principles to Practice. Wallingford: CABI International.

Saxena, G., \& Ilbery, B. (2008). Integrated rural tourism: A border case of study. Annals of Tourism Research, 35(1), 233-254.

Seguí, M. (2000). El turismo rural en las Islas Baleares. En La Actividad Turística Española en 1999. Edita AECIT, pp. 515-520.

Sharpley, J., \& Sharpley, R. (1997): Rural Tourism. An Introduction. London: International Thomson Business Press.

Tur, V. \& Garau, J. B. (2002). Agroturismo y Turismo Rural en Baleares. Palma de Mallorca: Estudis CAEB - CITTIB - Govern de les Illes Balears.

Valdés, L. (1996). El turismo rural en España. En Pedreño, A., \& Monfort, V. M. (ed.). Introducción a la Economía del Turismo en España. Madrid: Editorial Cívitas. pp 365-401.

Valdés, L., \& Del Valle, E. A. (2003). El turismo rural en España. Balance Global. En Curso avanzado de turismo en áreas rurales: Estrategias y promoción. 
Instituto Agronómico Mediterráneo de Zaragoza.

Williams, A., \& Shaw, G. (ed.) (1998). Tourism and Economic Development: European Experiences (3rd ed.). Chichester: Wiley.

Yagüe, R. M. (2002). Rural tourism in Spain. Annals of Tourism Research, 29(4), 11011110. 